BULLETIN Bulletin hispanique

HISPANIQUE Université Michel de Montaigne Bordeaux

115-1 | 2013

Poésie et société en Espagne : 1650-1750

\title{
Cuentos morales, de Leopoldo Alas Clarín
}

Cátedra, Madrid, 2012

\section{Ángeles Ezama Gil}

\section{CpenEdition}

Journals

Edición electrónica

URL: http://journals.openedition.org/bulletinhispanique/2588

DOI: $10.4000 /$ bulletinhispanique.2588

ISSN: 1775-3821

Editor

Presses universitaires de Bordeaux

\section{Edición impresa}

Fecha de publicación: 1 junio 2013

Paginación: 379-381

ISBN: 978-2-86781-898-1

ISSN: 0007-4640

Referencia electrónica

Ángeles Ezama Gil, «Cuentos morales, de Leopoldo Alas Clarín», Bulletin hispanique [En línea], 115-1 | 2013, Publicado el 08 diciembre 2013, consultado el 22 septiembre 2020. URL : http://

journals.openedition.org/bulletinhispanique/2588; DOI : https://doi.org/10.4000/bulletinhispanique. 2588

Este documento fue generado automáticamente el 22 septiembre 2020

Tous droits réservés 


\section{Cuentos morales, de Leopoldo Alas Clarín}

Cátedra, Madrid, 2012

Ángeles Ezama Gil

\section{REFERENCIA}

Cuentos morales, de Leopoldo Alas Clarín. Edición de Jean-François Botrel. Madrid, Cátedra, 2012.

1 Era necesaria una edición anotada de esta significativa colección de cuentos de Clarín, tan definitoria del hombre y del intelectual que fue Leopoldo Alas. Mucho se han editado los cuentos del escritor asturiano, en particular a partir de los años 80 del pasado siglo, sobre todo en antologías, pero también en colecciones de Cuentos completos y en la de Obras selectas y Obras completas; con todo, en lo que respecta a las ediciones de colecciones de cuentos anotadas, que arrojen un poco de luz sobre cómo trabajaba el Clarín cuentista, hay todavía mucho por hacer. Y esta edición de Jean-François Botrel, tan largamente meditada y tan concienzudamente llevada a cabo, supone sin duda un hito para la comprensión del arte del cuento en uno de los mejores escritores de cuentos españoles de todos los tiempos.

2 El trabajo de edición de una colección de cuentos es sin duda útil y sobre todo en una del calado de Cuentos morales, puesto que, a pesar de que los relatos que lo integran tienen todos ellos un origen periodístico, la colección de 1896 tiene una coherencia que no tienen otras del autor, que viene determinada en buena medida por el «Prólogo» (es la única colección clariniana que lo tiene), por la estrecha vinculación del libro con su autor y por constituir una especie de síntesis del universo clariniano, como señala Botrel citando a Pilar Palomo.

3 La introducción, impecable, da buena cuenta de cómo el trabajo del Clarín cuentista guarda estrecha relación con el del Clarín articulista, amparados ambos por el medio periodístico; el trabajo de Marie-Ève Thérenty sobre La littérature au quotidien (2007), 
citado por Botrel, se cuenta entre las aportaciones más novedosas a esta lectura clariniana, si bien no lo son menos las consideraciones del editor, buen conocedor del terreno que pisa, sobre las fases pre-redaccional, redaccional y editorial del proceso de edición, para lo que maneja manuscritos de diez de los cuentos de la colección, que se conservan en el archivo Tolívar. De todo ello resulta, señala el editor, que «el cuento es, pues, un artículo y algo más que un artículo» (p. 20). Otra de las lecturas sugestivas que aporta el prólogo es la que concierne a la ironía, por ser este uno de los puntales de la escritura clariniana; la aportación de Carole Fillière al respecto (L'esthétique ironique de Lepoldo Alas «Clarín», 2011), que Botrel señala, es sin duda otro hito fundamental para la interpretación. La atención a la interioridad del ser humano y el lirismo de la prosa se señalan muy acertadamente como los signos definitorios de estos cuentos, que corroboran la unidad del conjunto.

No hay que decir que tratándose de Botrel, la bibliografía es todo lo completa que se requiere; es particularmente interesante y curioso el apartado de bibliografía primaria en que se recogen, por orden cronológico, ediciones de los cuentos morales de Clarín en diversas lenguas, desde la primera de 1896 hasta la de Caudet en 2010, incluyendo ediciones exentas de los relatos o antologías en los que figuran determinados cuentos.

En la edición de los textos el editor ha respetado la mayoría de los signos diacríticos con que Clarín puntuó sus relatos, ya que más allá de usos de época, estos signos distan mucho de ser usados arbitrariamente; el autor con frecuencia les dotó de un sentido preciso que prolonga el sentido del relato más allá de las palabras. El respeto a las cursivas es también fundamental, ya que tienen la misma función que he señalado para los signos diacríticos.

6 La anotación de los textos es sin embargo mucho más discutible, como indudablemente toda anotación lo es. El propio Botrel ya había advertido sobre las dificultades de «Editar un clásico contemporáneo» en un trabajo suyo de 2008. Para Cuentos morales señala que son «notas ceñidas a la correcta interpretación de la palabra o del pasaje, sin excesiva y superflua erudición, con, en algún caso, referencias a unas posibles intertextualidades internas» (p. 84), teniendo en cuenta el público a que se destina «al aprendiz de hispanista francés, por ejemplo» (Ibíd.).

7 No es responsable el editor, desde luego, del sistema de anotación impuesto por la editorial Cátedra, por el que se mezclan distintos tipos de notas en una misma serie con numeración seguida: textuales, de aclaración de términos, de contextualización, o relativos a la fragmentación de los relatos para su edición periodística; ello induce a una cierta confusión del lector.

8 Por otra parte, el lugar donde se colocan las notas no es, con frecuencia, el más adecuado: a veces se anticipa la nota al propio discurso del texto que la explica, v.gr. la frase latina Fiat jus et ruat coelum se anota inmediatamente después de la frase (n. 34), aunque el propio texto la explica a continuación: «Cúmplase la ley, y húndase el cielo», con lo que la anotación resulta redundante; lo propio sucede con la expresión bable echar la persona en n. 631, que se anticipa a su explicación en el texto del cuento: «no eran tan recatadas que no echaran la persona (galanteo redicho, conceptuoso, a lo galán de Moreto), con diez o doce en una sola noche». Asimismo, se agradecería que algunas referencias se anotaran en el primer cuento en que aparecen: así, en «El cura de Vericueto» no se anotan los sepulcros blanqueados en p. 118 (Mateo 23, 27-32) pero sí en «Ordalías», n. 701 con una cita de Hechos, 23, 3, escasamente relevante; en el mismo 
relato (p. 125) falta la nota a mozo de cordel, que sí se incluye en «La conversión de Chiripa», n. 210.

9 Si hay dos relatos especialmente complicados de anotar en Cuentos morales son sin duda Vario y El cura de Vericueto; el primero por su detallada ambientación clasicista, es un relato que podríamos motejar de «erudito», si bien la interpretación de Richmond (Vario... y varia: Clarin a través de cinco cuentos suyos, 1990) y la edición de Ezama (Clarín, Cuentos, 1997) lo habían ya contextualizado de modo bastante ajustado; el segundo, por su tendencia al juego verbal y al uso de la ironía es un relato complejo en el plano discursivo y nada fácil de anotar sin excesos pero también sin carencias.

Creo que el editor ha sido excesivamente cauto para no sobreanotar los textos, por lo que en ocasiones se echa en falta la anotación de términos, citas o expresiones que probablemente el lector medio actual no entienda, v.gr. peluconas (p. 113), hierocráticas (p. 126), caciques de campanario en p. 143, una nota sobre Comte y las tres edades de la humanidad en p. 226 o un comentario al refrán implícito el que nace para ochavo no puede llegar a cuarto en p. 328.

11 Por último, creo que algunas notas habrían podido documentarse de modo un poco más exacto, v.gr. la 136: existió más de una Biblioteca Diamante en el siglo XIX (años 60, años 80-90), que no es la misma que la Colección Diamante editada por Antonio López en Barcelona a partir de 1894, pero a la que a menudo se alude en la prensa como Biblioteca Diamante; la 496 sobre el duque de los abrazos: no digo que no haya un eco del abrazo de Vergara, pero Luis Amadeo de Saboya tenía el título de duque de los Abruzos; o la 862: Maud de Gales, la duquesa de York (María de Teck) y la reina de Italia (Margarita Teresa de Saboya) no son la misma persona sino tres distintas.

Por último, creo que son muy útiles los apéndices que muestran fragmentos de la escritura clariniana y de las ediciones en prensa y en libro, y recogen el perspicaz artículo de Gómez de Baquero sobre Cuentos morales.

Una edición más que recomendable, por tanto, aun cuando no siempre se esté de acuerdo con el criterio que preside la anotación.

\section{AUTORES}

\section{ÁNGELES EZAMA GIL}

Universidad de Zaragoza 